\section{A) Check for updates}

Cite this: Org. Chem. Front., 2021, 8 . 5722

Received 18th June 2021,

Accepted 10th August 2021

DOI: 10.1039/d1qo00919b

rsc.li/frontiers-organic

\title{
An expedient, mild and aqueous method for Suzuki-Miyaura diversification of (hetero)aryl halides or (poly)chlorinated pharmaceuticals $\uparrow$
}

\author{
Sunil V. Sharma, (D) * Cristina Pubill-Ulldemolins, (D) * Enrico Marelliø and \\ Rebecca J. M. Goss (iD *
}

\begin{abstract}
The development of mild, aqueous conditions for the cross-coupling of highly functionalized (hetero)aryl chlorides or bromides is attractive, enabling their functionalization and diversification. Herein, we report a general method for Suzuki-Miyaura cross-coupling at $37{ }^{\circ} \mathrm{C}$ in aqueous media in the presence of air. We demonstrate application of this general methodology for derivatisation of (poly)chlorinated, medicinally active compounds and halogenated amino acids. The approach holds the potential to be a useful tool for late-stage functionalization or analogue generation.
\end{abstract}

\section{Introduction}

Palladium-catalysed cross-coupling reactions have become indispensable methodologies for the formation of $\mathrm{C}-\mathrm{C}$ and carbon-heteroatom bonds under mild conditions with a wide range of organic halide and nucleophilic reagents. Palladiumcatalysed cross-coupling reactions have largely utilised traditional organic solvents; the standard conditions for the Suzuki-Miyaura coupling typically require an organic, or mixed organic/aqueous base solvent system. ${ }^{1,2}$ The first example of a water-soluble palladium catalyst for cross-coupling reactions was reported by Casalnuovo. ${ }^{3}$ Significant effort has been devoted to the development of hydrophilic palladium/ligand complexes for aqueous-phase catalysis since this seminal work. In recent years, there has been increasing interest in the use of aqueous conditions in which hydrophobic catalysts are used with water as the reaction medium, as well as ligand-free catalysts based on palladium nanoparticles. ${ }^{4-7}$ The development of mild and functionally tolerant cross-coupling conditions for the modulation of challenging compounds is attractive, enabling the diversification of bioactive compounds, natural products and peptides.

School of Chemistry and BSRC, University of St Andrews, St Andrews, KY16 9ST, UK. E-mail: rjmg@st-andrews.ac.uk,svs4@st-andrews.ac.uk

$\dagger$ This research work was carried out at the University of St Andrews.

\$Electronic supplementary information (ESI) available. See DOI: 10.1039/ d1qo00919b

$\S$ Current address: Department of Chemistry, School of Life Sciences, University of Sussex, Brighton, BN1 9QJ. UK. C.Pubill-Ulldemolins@sussex.ac.uk.

ๆCurrent address: Laboratoire Hétérochimie Fondamentale et Appliquée, Université Paul Sabatier, 31062 Toulouse, France.

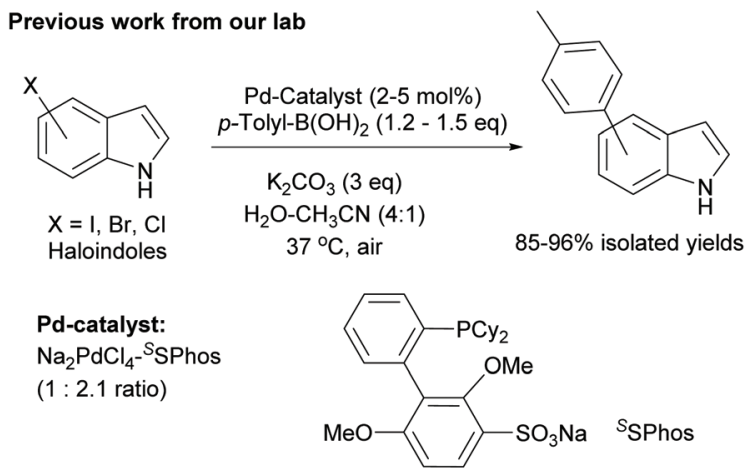

This work

Applications towards analogue generation<smiles>[R]c1ccccc1NO</smiles>

Aryl/Heterocyclic boronic acids<smiles>[R]c1cc(C(F)(F)Cl)cnc1-c1ccccc1</smiles>

Aryl/Heterocyclic halides
BocHN,

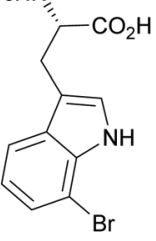

$N$-Protected bromotryptophan
Applications towards late-stage derivatisation of pharmaceuticals

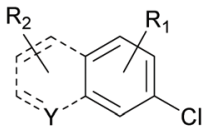

Highly functionalised chlorinated drugs<smiles>[R]c1ccc([Y]([H])c2ccc(Cl)cc2Cl)cc1</smiles>

Trichlorinated bioactive compounds
Scheme 1 Aqueous, aerobic Suzuki-Miyaura cross-coupling methodology applied for derivatisation of various brominated/chlorinated (hetero) aryl compounds and chlorinated active pharmaceutical ingredients (APIs). 
Since developing the first Suzuki-Miyaura cross-coupling of unprotected chloro-/bromo-tryptophans ${ }^{8}{ }^{8}$ we reported the aqueous methodologies for Sonogashira, ${ }^{9}$ Heck, ${ }^{10}$ BuckwaldHartwig amination ${ }^{11}$ and ketoarylation ${ }^{12}$ coupling chemistries. We also showed that Suzuki-Miyaura modification could be utilised to modulate the fluorescence properties of tryptophans, ${ }^{8}$ which was further exploited as an assay to detect the halogenases enzyme activity by Sewald $e t a l .{ }^{13}$ Subsequently we used the aqueous cross-coupling procedures, in a GenoChemetics approach, for natural product derivatization using chloropacidamycin, which was biosynthetically generated by installing a halogenase into the pacidamycins producing bacteria, Streptomyces coeruleorubidis. ${ }^{14}$ The O'Connor group further exemplified this approach in the synthetic modification of plant natural products using chlorinated-alkaloids. ${ }^{15}$ Applications of Suzuki-Miyaura cross-coupling procedures, focused on halotryptophans, could be translated to the modulation of peptides. ${ }^{16,17}$ We also reported the generation and modification of new to nature halogenated natural products in living cells and subsequently cross-couple the halo-metabolites in living bacterial cultures. ${ }^{18}$

Such advanced applications of cross-coupling methodologies require development of operationally simple, mild, aqueous reactions effective at physiological temperatures and in the presence of air. Within this context, we have successfully demonstrated that $\mathrm{Pd} /{ }^{S} \mathrm{SPhos}$ catalyst is effective for the coupling of chloroindoles with $p$-toluene boronic acid in aqueous solvent at $37{ }^{\circ} \mathrm{C} .{ }^{18}$ These results prompted us to extend this study and establish its application for a wide variety of (hetero) aromatic coupling partners and for derivatization of medicinally useful (poly)chlorinated pharmaceuticals.

\section{Results and discussion}

Initially, we focused on establishing water and air compatible reaction conditions for the cross-coupling of brominated and chlorinated indoles as model compounds. The indole heterocyclic moiety is a previleged motif, which is present in proteins in the form of the amino acid tryptophan, and in many bioactive compounds and natural products. There is some precedence for cross-coupling of haloindoles at mild temperatures, including the cross-coupling of 5 -chloroindole at $40{ }^{\circ} \mathrm{C}$ in degassed THF. ${ }^{19}$ However, we aimed to establish a mild and general method for Suzuki-Miyaura cross-coupling under aqueous-aerobic conditions that is suitable for derivatization of unprotected heterocyclic and highly functionalized bioactive compounds. In this context, after systematically screening for the Pd-source/ligand/base/co-solvent, we identified that a combination of water-soluble palladium salt $\left(\mathrm{Na}_{2} \mathrm{PdCl}_{4}\right)$ with readily available sulphonated phosphine ligand ( $\left({ }^{S} \mathrm{SPhos}\right)$ and $\mathrm{K}_{2} \mathrm{CO}_{3}$ base was optimal for cross-coupling of haloindoles with $p$-tolyl-B $(\mathrm{OH})_{2}$ in $4: 1$ water-acetonitrile mixture at $37{ }^{\circ} \mathrm{C}$ (Scheme 1 previous work ${ }^{18}$ and see Table S1, ESI $\$$ for details). The ligand was essential, no reaction was observed for 5-bromo/chloroindole using the Pd-salt without ${ }^{S} \mathrm{SPhos}$. This indicated a critical role of ${ }^{S}$ SPhos towards activation of Pd as well as subsequent oxidative addition under mild reaction conditions..$^{20}$ Due to relatively poor aqueous solubility, (hetero)aryl chlorides formed a suspension in water-acetonitrile $(4: 1)$. Addition of Pd- ${ }^{S}$ SPhos solution resulted in a cloudy non-homogenous mixture. Upon completion of the reaction, a black precipitate was always observed. When analysed, reactions in which precipitation did not occur were seen to have afforded no product. Based on these observations, we propose that the reaction is initiated by $\mathrm{Pd}^{S}{ }^{S} \mathrm{SPhos}$ akin to homogenous catalysis - however, during the course of reaction, we speculate formation of mixed Pd-species that play a role in catalysis. ${ }^{21}$ As our objective was catalytic utility, rather that determining the exact mechanism of the reactions, we further explored the synthetic utility of these mild conditions to diversify a wide range of scaffolds.

\section{Scope of (hetero)aryl boronic acids}

Heterocyclic structures not only privileged compounds, but are often key fragments of many biologically active molecules. Many alkaloid natural products, such as reserpine (antihypertensive), serotonin (neurotransmitter), vinblastine (anticancer), contain the indole moiety. ${ }^{22}$

Several clinically useful marketed drugs containing indoles include indomethacin (anti-inflammatory), delavirdine (antiHIV) and panobinostat (anticancer). ${ }^{23}$ To establish the general applicability of our cross-coupling conditions, we explored the reaction scope of a range of aryl boronic acids using 5-bromoindole as the halogenated heterocyclic substrate.

Unprotected haloindoles are often challenging substrates for Pd-catalysed cross-coupling reactions due to free $\mathrm{N}-\mathrm{H}$ groups, while suffering from a drawback of lower isolated yields due to potential side reactions (intermolecular coupling between $\mathrm{NH}$ and $\mathrm{C}-\mathrm{X}$ ) producing oligomers. ${ }^{11,12}$ It is noteworthy that this problem was not observed using our mild, aqueous Suzuki-Miyaura protocol in this study. In most cases, full conversions were observed, and lower isolated yield for $2 \mathbf{e}$ and $2 \mathbf{f}$ can be accounted to loss of material during chromatographic purifications. A variety of aryl boronic acids were well tolerated, affording $60-98 \%$ isolated yields of the target crosscoupling products (Scheme 2).

The reactions with electron-rich ( $p$-methoxyphenyl, $p$-tolyl) as well as sterically encumbered ( $o$-tolyl) boronic acids proceeded well ( $>92 \%$ isolated yields, $2 a-2 c)$. The reaction with electron-deficient and generally less favoured $o$-nitrophenylboronic acid worked well (84\% yield, 2d). Other challenging coupling partner, quinoline-3-boronic acid, afforded the crosscoupling product $2 \mathrm{e}$ in $62 \%$ yield. This low recovery of desired product was attributed to relatively poor solubility of heterocyclic boronic acid in mild, aqueous system as well as the need to repeat chromatographic purification steps. On the other hand, the reaction using fluorescent coupling partner, dansyl3-aminophenylboronic acid (dansyl: [3-[5-(dimethylamino) naphthalen-1-yl]]), was found to be sluggish and $85 \%$ NMR yield was observed for $2 \mathrm{f}$ after $36 \mathrm{~h}$ at $37^{\circ} \mathrm{C}$, whereas the isolated yield was moderate $(60 \%)$. This method was generally 


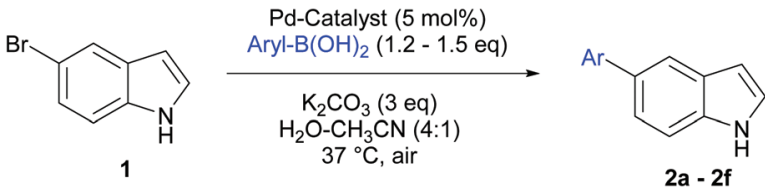<smiles>Cc1ccc(-c2ccc3[nH]ccc3c2)cc1</smiles>

2a $92 \%(95 \%)^{\mathrm{a}}$<smiles>Cc1ccccc1-c1ccc2[nH]ccc2c1</smiles>

2c $98 \%$<smiles>c1ccc2ncc(-c3ccc4[nH]ccc4c3)cc2c1</smiles>

2 e $62 \%^{b}$<smiles>COc1ccc(-c2ccc3[nH]ccc3c2)cc1</smiles>

2b $98 \%$<smiles>O=[N+]([O-])c1ccccc1-c1ccc2[nH]ccc2c1</smiles>

$2 \mathrm{~d} 84 \%$<smiles>CN(C)c1cccc2c(NS(=O)(=O)Nc3cccc(-c4ccc5[nH]ccc5c4)c3)cccc12</smiles>

Scheme 2 Scope of aryl boronic acids in Suzuki-Miyaura cross-coupling with 5-bromoindole. Reaction conditions: Haloindole $(0.1 \mathrm{mmol})$, appropriate $\mathrm{ArB}(\mathrm{OH})_{2}(0.12-0.15 \mathrm{mmol}), \mathrm{K}_{2} \mathrm{CO}_{3}(0.3 \mathrm{mmol}), \mathrm{Pd} /{ }^{5} \mathrm{Sphos}$ (5 mol\%) in water-acetonitrile $(4: 1,1 \mathrm{~mL}), 37^{\circ} \mathrm{C}, 18 \mathrm{~h}$. Isolated yields are

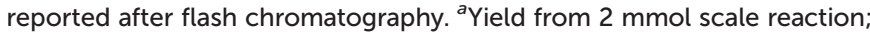
${ }^{b}$ two chromatographic purification steps required to isolate pure product; ${ }^{C}$ reaction was carried out for $36 \mathrm{~h}$.

applicable for cross-coupling of unprotected indolic halides with various aryl boronic acids and the fluorescence tagging of aryl halides under very mild conditions.

\section{Substrate scope: coupling of various (hetero)aromatic aryl halides}

Next, we turned our attention to the scope of aryl halides as coupling partners. As depicted in Scheme 3, a range of aryl, heteroaryl bromides or chlorides were successfully coupled with $p$-tolyl boronic acid to deliver the corresponding biaryl compounds. Most reactions gave full conversion after overnight stirring at $37^{\circ} \mathrm{C}$. In general, 1.5 equiv. (not optimized for each substrate) $p$-tolyl- $\mathrm{B}(\mathrm{OH})_{2}$ sufficed to achieve full conversion.

The mild, aqueous catalytic conditions were tolerant to a variety of functional groups, heterocycles and N-protected tryptophan substrates. Activated aryl chloride possessing electron-withdrawing groups ( $p$-formyl or methylsulfoxide, $\mathbf{4 a}, \mathbf{4 b}$ ) as well as deactivated aryl bromide (with electron-donating

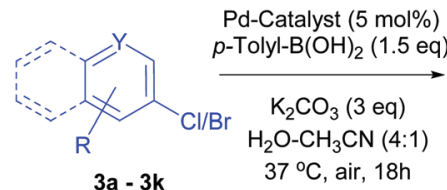<smiles>[R]C1=CC=CC=c2[Y]cc(-c3ccc(C)cc3)cc21</smiles>

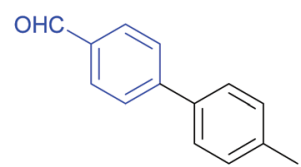

$4 a>99 \%$ (from $-\mathrm{Cl}$ )<smiles>Cc1ccc(-c2ccc(N(C)C)cc2)cc1</smiles><smiles>CC(=O)c1cccc(-c2ccc(C)cc2)n1</smiles>

4 e $>99 \%$ (from $-\mathrm{Br}$ )<smiles>Cc1ccc(-c2cncnc2)cc1</smiles>

4 g $96 \%$ (from $-\mathrm{Br}$ )<smiles>COS(=O)(=O)c1ccc(-c2ccc(C)cc2)cc1</smiles>

$4 b>99 \%($ from $-\mathrm{Cl})$

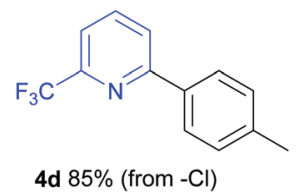<smiles>Cc1ccc(-c2cccc(C(N)=O)n2)cc1</smiles>

4 f $>99 \%$ (from $-\mathrm{Br}$ )

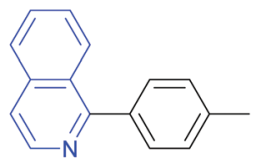

4h $92 \%$ (from $-\mathrm{Br}$ )<smiles>Cc1ccc(-c2ccc3oc(C)nc3c2)cc1</smiles>

4i $67 \%$ (from $-\mathrm{Cl}$ )

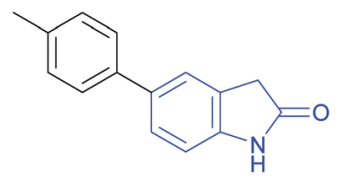

4j no reaction at $37^{\circ} \mathrm{C}$ $63 \%\left(\mathrm{MW}, 80^{\circ} \mathrm{C} \text {, from }-\mathrm{Cl}\right)^{\mathrm{a}}$<smiles>Cc1ccc(-c2cccc3c(C[C@H](NC(=O)O)C(=O)O)c[nH]c23)cc1</smiles>

4k $65 \%(\text { from }-\mathrm{Br})^{\mathrm{b}}$

Scheme 3 Scope of aryl halides in Suzuki-Miyaura cross-coupling with p-tolyl boronic acid. Reaction conditions: Aryl halide $(0.1 \mathrm{mmol})$, p-tolyl- $\mathrm{B}(\mathrm{OH})_{2}(0.15 \mathrm{mmol}), \mathrm{K}_{2} \mathrm{CO}_{3}(0.3 \mathrm{mmol}), \mathrm{Pd} /{ }^{S} \mathrm{Sphos}(5 \mathrm{~mol} \%)$ in water-acetonitrile $(4: 1,1 \mathrm{~mL}), 37^{\circ} \mathrm{C}, 18 \mathrm{~h}$. Isolated yields are reported after flash chromatography. ${ }^{a}$ No conversion was observed at $37{ }^{\circ} \mathrm{C}$. Reported yield for the reaction conducted for $1 \mathrm{~h}$ at $80^{\circ} \mathrm{C}$ using microwave heating; ${ }^{b}$ Reaction was conducted at $37^{\circ} \mathrm{C}$ for $24 \mathrm{~h}$ using $p$-tolyl$\mathrm{B}(\mathrm{OH})_{2}$ (3 equiv.) and $\mathrm{K}_{2} \mathrm{CO}_{3}$ (6 equiv.).

p-dimethylamino group, 4c) worked well and the corresponding products were isolated in quantitative yields.

Pyridine is a common heterocyclic motif found in pharmaceutically active compounds and natural products, hence, mild 
synthetic methods for pyridine and heterocyclic derivatives are desirable. ${ }^{24}$ Our reaction protocol translated well to the crosscoupling of various chloro-/bromo-pyridines elaborated with acetyl or carboxamido substituents, providing near quantitative yields of the target products $(\mathbf{4 e}, \mathbf{4 f})$; whilst the cross-coupling of trifluoromethyl substituted pyridyl-chloride resulted in an excellent yield of $85 \%$ (4d).

Consistent with the above results, 1-bromoisoquinoline and 5 -bromopyrimidine afforded the coupling products $\mathbf{4 h}(92 \%)$ and $\mathbf{4 g}(96 \%)$ respectively. Disappointingly, under these mild reaction conditions, no coupling was observed for the very electron rich 5-chloro-2-oxyindole $(\mathbf{4 j})$ at $37{ }^{\circ} \mathrm{C}$ even after prolonged reaction times. However, a satisfying $63 \%$ yield of $5-(p$ tolyl)-2-oxyindole was obtained after microwave heating for $1 \mathrm{~h}$ at $80^{\circ} \mathrm{C}$.

A literature search (Scifinder) did not reveal any published report of the Suzuki-Miyaura coupling of free 5-chloro-2-oxyindole, and the oxidative addition is likely to be particularly demanding, or unattainable at $37{ }^{\circ} \mathrm{C}$ for such a substrate. On the other hand, good conversion was observed for the coupling of 6-chloro-2-methylbenzoxazole, albeit, relatively lower yield $(\mathbf{4 i}, 67 \%)$ was isolated. Considering the electron rich nature of benzoxazolyl chloride, and mild reaction conditions at $37^{\circ} \mathrm{C}$, this result is very encouraging and demonstrates a wide applicability of our protocol.

The Pd-mediated coupling of unprotected halotryptophans is challenging due to solubility issues, as well as the chelation of the catalyst. ${ }^{18}$ Our attempts to cross-couple the fully unprotected 5- or 7-bromotryptophan, using this general protocol, were unsuccessful. To achieve the desired reaction for this challenging substrate, we employed N-protected bromotryptophan. Indeed, repeating the reaction with $N$-boc-7-bromotrytpophan, a full conversion was observed within $24 \mathrm{~h}$ using 3 equiv. $p$-Tol- $\mathrm{B}(\mathrm{OH})_{2}$ and the product $4 \mathbf{k}$ was isolated in a respectable $65 \%$ yield. This lower isolated yield could be due to purification challenges. All these examples indicate the versatile applications of this mild cross-coupling protocol.

\section{Direct cross-coupling of chloroarenes in pharmaceuticals and bioactive ( poly)chlorides}

To determine the applicability of this catalytic system on increasingly challenging substrates, an explorative study on more elaborate substrates was undertaken. Many over-thecounter drugs (OTC drugs) possess aryl chloride or heteroaryl chloride motif. We applied our mild cross-coupling protocol for pharmaceutically relevant chlorinated compounds and drugs. Using our optimised conditions, several OTC drugs were successfully converted to corresponding cross-coupling products in high to excellent yields.

The structural diversity and functional group complexity of all the chlorinated aromatic substrates screened is evident from Scheme 4.

Clotrimazole (5a, an azole antifungal possessing benzylic imidazole ring), prochlorperazine ( $\mathbf{5 b}$, dopamine antagonist containing chlorophenothiazine heterocycle with a side chain piperidine) and indomethacin (5c, non-steroidal anti-inflam-

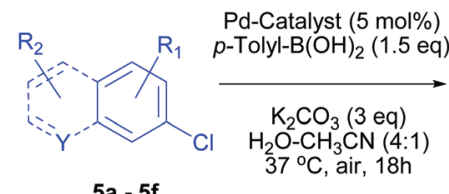

$5 a-5 f$

Highly functionalised chlorinated drugs

\section{Substrate}<smiles>Clc1ccccc1C(c1ccccc1)(c1ccccc1)n1ccnc1</smiles>

Clotrimazole (5a)<smiles>CN1CCN(CCCN2c3ccccc3Sc3ccc(Cl)cc32)CC1</smiles>

Prochlorperazine (5b)

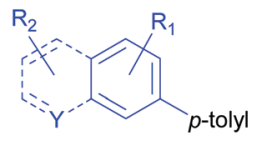

$6 a-6 f$<smiles>COc1ccc2c(c1)c(CC(=O)O)c(C)n2C(=O)c1ccc(Br)cc1</smiles>

Product<smiles>O=[W]c1ccccc1C(c1ccccc1)(c1ccccc1)n1ccnc1</smiles>

6a $88 \%$

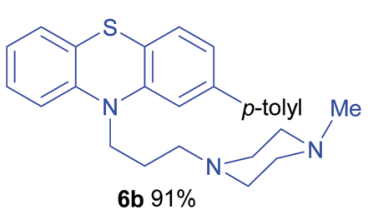

6b $91 \%$<smiles>COc1ccc2c(c1)c(CC(=O)O)c(C)n2C(=O)c1ccc(OC(=O)O)cc1</smiles>

6c $71 \%$<smiles>COC1=CC(=O)C[C@H](C)[C@]12Oc1c(Cl)c(OC)cc(OC)c1C2=O</smiles>

Griseofluvin (5d)

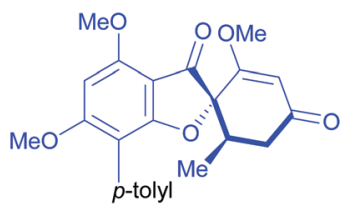

$6 \mathrm{~d}$ no reaction

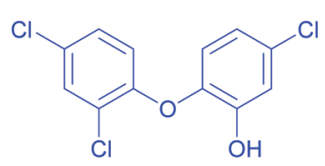

Irgasan (Triclosan, 5e)

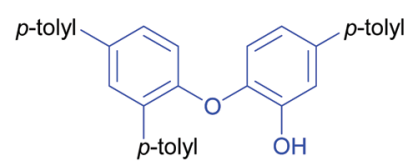

6 e $85 \%$

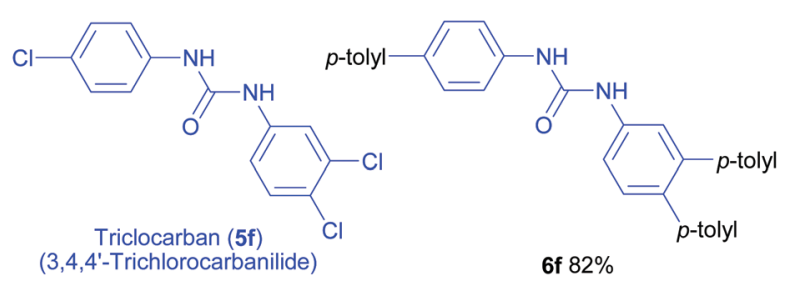

Scheme 4 Suzuki-Miyaura cross-coupling of (poly)chlorinated overthe-counter drugs and medicinal agents. Reaction conditions: Aryl chloride $(0.1 \mathrm{mmol}), p$-tolyl- $\mathrm{B}(\mathrm{OH})_{2} \quad(0.15 \mathrm{mmol} / \mathrm{Cl}), \mathrm{K}_{2} \mathrm{CO}_{3}$ $(0.3-0.6 \mathrm{mmol}), \mathrm{Pd} /{ }^{\mathrm{S}} \mathrm{Sphos}(5 \mathrm{~mol} \%)$ in water-acetonitrile $(4: 1,1 \mathrm{~mL})$, $37^{\circ} \mathrm{C}, 18 \mathrm{~h}$ ( $36 \mathrm{~h}$ for trichloro substrates). Isolated yields are reported after flash chromatography. No conversion was observed for $5 \mathrm{~d}$ at $37^{\circ} \mathrm{C}$ even after prolonged time. 
matory drug, an indole analogue with a free carboxylic acid) were successfully functionalised and high isolated yields (88, 91 and 71\% respectively, 6a-6c, Scheme 4) were obtained under mild conditions. The methodology was further challenged by testing against irgasan (5e, antimicrobial), an electron-rich trichlorinated phenolic ether. Gratifyingly, irgasan successfully underwent coupling at each of chlorides (85\% isolated yield) using 4.5 equiv. $p$-Tol- $\mathrm{B}(\mathrm{OH})_{2}$. However, purification of these complex compounds was challenging due to co-elution/complexation of homocoupled by-product ( $p, p^{\prime}$-bitoluene), presumably due to pi-pi stacking with polyarylated products.

For the challenging chloroarylurea substrate 5f, very few Pdcatalysed Suzuki-Miyaura cross-couplings are known. These protocols required either high temperature in organic solvents (90-150 ${ }^{\circ} \mathrm{C}$ ), or elaborate degassing and tedious reaction set-up or use bespoke (non-commercial) catalysts. ${ }^{25,26}$

Using the reaction conditions developed in this study, a complete conversion was obtained for triclocarban (5f, antimicrobial, an aryl trichloride possessing a urea motif) and the tris-coupling product 6 f was isolated in $82 \%$ yield, proving the utility of this mild protocol for complex transformations. Unfortunately, sterically demanding and highly electron-rich aryl chloride (griseofulvin) failed to afford any cross-coupling product. Only unreacted starting material was recovered indicating lack of oxidative addition under the mild reaction conditions. Only 3 examples of Suzuki-Miyaura elaboration of griseofulvin are reported under forcing conditions at temperatures $>100{ }^{\circ} \mathrm{C} .{ }^{27-29}$ Regardless, above results highlight the strength of our mild cross-coupling methodology towards the potential applications for functionalisation of medicinal compounds.

\section{Conclusions}

In conclusion, we report a straightforward and mild protocol for the Suzuki-Miyaura cross-coupling of various (hetero)aryl chlorides/bromides, including N-protected halotryptophan with a variety of aryl boronic acids. The cross-couplings were achieved in aqueous conditions, in the presence of air, at $37^{\circ} \mathrm{C}$. Importantly, these conditions could also be applied successfully to the modification of highly functionalized (poly) chlorinated pharmaceuticals, potentially opening ways towards the direct cross-coupling of halogenated molecules, using commercially available catalyst, under exceptionally mild conditions.

\section{Conflicts of interest}

There are no conflicts to declare.

\section{Acknowledgements}

The research leading to these results has received funding from the European Research Council under the European
Union's Seventh Framework Programme (FP7/2007-2013/ERC grant agreement no 614779 GenoChemetics (to R.J.M.G). The EPSRC National Mass Spectrometry Facility (Swansea, UK) is acknowledged for the recording of HRMS.

\section{Notes and references}

1 N. Miyaura and A. Suzuki, Palladium-Catalyzed CrossCoupling Reactions of Organoboron Compounds, Chem. Rev., 1995, 95, 2457-2483.

2 J. P. Corbet and G. Mignani, Selected patented cross-coupling reaction technologies, Chem. Rev., 2006, 106, 26512710.

3 A. L. Casalnuovo and J. C. Calabrese, Palladium-catalyzed alkylations in aqueous media, J. Am. Chem. Soc., 1990, 112, 4324-4330.

4 T. E. Schmid, D. C. Jones, O. Songis, O. Diebolt, M. R. L. Furst, A. M. Z. Slawin and C. S. J. Cazin, Mixed phosphine/N-heterocyclic carbene palladium complexes: Synthesis, characterization and catalytic use in aqueous Suzuki-Miyaura reactions, Dalton Trans., 2013, 42, 73457353.

5 G. Hervé, G. Sartori, G. Enderlin, G. MacKenzie and C. Len, Palladium-catalyzed Suzuki reaction in aqueous solvents applied to unprotected nucleosides and nucleotides, $R S C$ Adv., 2014, 4, 18558-18594.

6 B. H. Lipshutz, T. B. Petersen and A. R. Abela, Room-temperature Suzuki-Miyaura couplings in water facilitated by nonionic amphiphiles, Org. Lett., 2008, 10, 1333-1336.

7 A. Fihri, M. Bouhrara, B. Nekoueishahraki, J. M. Basset and V. Polshettiwar, Nanocatalysts for Suzuki cross-coupling reactions, Chem. Soc. Rev., 2011, 40, 5181-5203.

8 A. D. Roy, R. J. M. Goss, G. K. Wagner and M. Winn, Development of fluorescent aryltryptophans by $\mathrm{Pd}$ mediated cross-coupling of unprotected halotryptophans in water, Chem. Commun., 2008, 4831-4833.

9 M. J. Corr, S. V. Sharma, C. Pubill-Ulldemolins, R. T. Bown, P. Poirot, D. R. M. Smith, C. Cartmell, A. Abou Fayad and R. J. M. Goss, Sonogashira diversification of unprotected halotryptophans, halotryptophan containing tripeptides; and generation of a new to nature bromo-natural product and its diversification in water, Chem. Sci., 2017, 8, 20392046.

10 C. Pubill-Ulldemolins, S. V. Sharma, C. Cartmell, J. Zhao, P. Cárdenas and R. J. M. Goss, Heck diversification of indole-based substrates under aqueous conditions: From indoles to unprotected halo-tryptophans and halo-tryptophans in aatural product derivatives, Chem. - Eur. J., 2019, 25, 10866-10875.

11 Y. J. G. Renault, R. Lynch, E. Marelli, S. V. Sharma, C. Pubill-Ulldemolins, J. A. Sharp, C. Cartmell, P. Cárdenas and R. J. M. Goss, Buchwald Hartwig diversification of unprotected halotryptophans, halotryptophan containing tripeptides and the natural product barettin in aqueous conditions, Chem. Commun., 2019, 55, 13653-13656. 
12 E. Marelli, Y. Renault, S. V. Sharma, S. P. Nolan and R. J. M. Goss, Mild, aqueous $\alpha$-arylation of ketones: Towards aew diversification tools for halogenated metabolites and drug molecules, Chem. - Eur. J., 2017, 23, 38323836.

13 C. Schnepel, H. Minges, M. Frese and N. Sewald, A highthroughput fluorescence assay to determine the activity of tryptophan halogenases, Angew. Chem., Int. Ed. Engl., 2016, 55, 14159-14163.

14 A. D. Roy, S. Gruschow, N. Cairns and R. J. M. Goss, Gene expression enabling synthetic diversification of natural products: Chemogenetic generation of pacidamycin analogs, J. Am. Chem. Soc., 2010, 132, 12243-12245.

15 W. Runguphan and S. E. O'Connor, Diversification of monoterpene indole alkaloid analogs through cross-coupling, Org. Lett., 2013, 15, 2850-2853.

16 T. Willemse, K. Van Imp, R. J. M. Goss, H. W. T. Van Vlijmen, W. Schepens, B. U. W. Maes and S. Ballet, SuzukiMiyaura diversification of amino acids and dipeptides in aqueous media, ChemCatChem, 2015, 7, 2055-2070.

17 I. Kemker, D. C. Schröder, R. C. Feiner, K. M. Müller, A. Marion and N. Sewald, Tuning the biological activity of RGD peptides with halotryptophans, J. Med. Chem., 2021, 64, 586-601.

18 S. V. Sharma, X. Tong, C. Pubill-Ulldemolins, C. Cartmell, E. J. A. Bogosyan, E. J. Rackham, E. Marelli, R. B. Hamed and R. J. M. Goss, Living GenoChemetics by hyphenating synthetic biology and synthetic chemistry in vivo, Nat. Commun., 2017, 8, 229.

19 M. A. Düfert, K. L. Billingsley and S. L. Buchwald, SuzukiMiyaura cross-coupling of unprotected, nitrogen-rich heterocycles: Substrate scope and mechanistic investigation, J. Am. Chem. Soc., 2013, 135, 12877-12885.

20 M. A. Dufert, K. L. Billingsley and S. L. Buchwald, SuzukiMiyaura Cross-Coupling of Unprotected, Nitrogen-Rich
Heterocycles: Substrate Scope and Mechanistic Investigation, J. Am. Chem. Soc., 2013, 135, 12877-12885.

21 J. Sherwood, J. H. Clark, I. J. S. Fairlamb and J. M. Slattery, Solvent effects in palladium catalysed cross-coupling reactions, Green Chem., 2019, 21, 2164-2213.

22 A. Kumari and R. K. Singh, Medicinal chemistry of indole derivatives: Current to future therapeutic prospectives, Bioorg. Chem., 2019, 89, 103021.

23 T. V. Sravanthi and S. L. Manju, Indoles-A promising scaffold for drug development, Eur. J. Pharm. Sci., 2016, 91, $1-10$.

24 J. Magano and J. R. Dunetz, Large-scale applications of transition metal-catalyzed couplings for the synthesis of pharmaceuticals, Chem. Rev., 2011, 111, 2177-2250.

25 G. R. Peh, E. A. B. Kantchev, J. C. Er and J. Y. Ying, Rational exploration of N-Heterocyclic carbene (NHC) palladacycle diversity: A highly active and versatile precatalyst for Suzuki-Miyaura coupling reactions of deactivated aryl and alkyl substrates, Chem. - Eur. J., 2010, 16, 4010-4017.

26 K. Evans, et al., Patent, WO2006052722A1, 2006.

27 T. Zhou, S. Ma, F. Nahra, A. M. C. Obled, A. Poater, L. Cavallo, C. S. J. Cazin, S. P. Nolan and M. Szostak, [Pd $(\mathrm{NHC})(\mu-\mathrm{Cl}) \mathrm{Cl}] 2$ : Versatile and Highly Reactive Complexes for Cross-Coupling Reactions that Avoid Formation of Inactive Pd(I) Off-Cycle Products, iScience, 2020, 23, 101377.

28 P. Y. Choy, O. Y. Yuen, M. P. Leung, W. K. Chow and F. Y. Kwong, A Highly Efficient Monophosphine Ligand for Parts per Million Levels Pd-Catalyzed Suzuki-Miyaura Coupling of (Hetero)Aryl Chlorides, Eur. J. Org. Chem., 2020, 2846-2853.

29 M. P. Leung, P. Y. Choy, W. I. Lai, K. B. Gan and F. Y. Kwong, Facile Assembly of Carbazolyl-Derived Phosphine Ligands and Their Applications in PalladiumCatalyzed Sterically Hindered Arylation Processes, Org. Process Res. Dev., 2019, 23, 1602-1609. 